\title{
Voluntary Smoke-Free Home Rules and Exposure to Secondhand Smoke in Poland: A National Cross-Sectional Survey
}

\author{
Mateusz Jankowski ${ }^{1,2}{ }^{\oplus}$, Jarosław Pinkas ${ }^{1}$, Wojciech S. Zgliczyński $\left.{ }^{1}{ }^{(}\right)$, Dorota Kaleta ${ }^{3}$, \\ Waldemar Wierzba ${ }^{4}$ (D), Mariusz Gujski ${ }^{5}$ and Vaughan W. Rees ${ }^{2, *(D)}$ \\ 1 School of Public Health, Centre of Postgraduate Medical Education, 01-826 Warsaw, Poland; \\ mjankowski@cmkp.edu.pl (M.J.); jpinkas@cmkp.edu.pl (J.P.); wzgliczynski2@cmkp.edu.pl (W.S.Z.) \\ 2 Center for Global Tobacco Control, Department of Social and Behavioral Sciences, Harvard T.H. \\ Chan School of Public Health, Boston, MA 02115, USA \\ 3 Department of Hygiene and Epidemiology, Medical University of Lodz, 90-647 Łódź, Poland; \\ dorota.kaleta@umed.lodz.pl \\ 4 UHE Satellite Campus in Warsaw, University of Humanities and Economics in Łódź, 01-513 Warsaw, Poland; \\ wwierzba@post.pl \\ 5 Department of the Prevention of Environmental Hazards and Allergology, Medical University of Warsaw, \\ 02-091 Warsaw, Poland; mariusz.gujski@wum.edu.pl \\ * Correspondence: vrees@hsph.harvard.edu; Tel.: +1-617-432-6345
}

Received: 2 September 2020; Accepted: 13 October 2020; Published: 15 October 2020

\begin{abstract}
Smoke-free policies have been shown to significantly reduce secondhand smoke (SHS) exposure in private and public places. The objectives of this study were to: (1) to assess the prevalence and characteristics of voluntary smoke-free home rules in Poland; and (2) assess the association of smoke-free rules with self-reported SHS exposure in private homes. A cross-sectional survey was conducted in September 2019 with a nationally representative sample of 1011 individuals aged 15 and over. Nationally, $66.1 \%$ of individuals had a $100 \%$ smoke-free home rule $(78.9 \%$ of non-smokers and $18.6 \%$ of smokers; $p<0.001$ ), while a further $24.6 \%$ had adopted a partial home smoking rule. SHS exposure in the home during past month was reported by $6.1 \%$ of respondents $(11.5 \%$ of smokers and $4.5 \%$ of non-smokers; $p<0.001)$. The lowest level of SHS exposure $(1.8 \%)$ was observed among respondents who had implemented a full smoke-free home rule. Non-smokers had higher odds of having adopted a total smoke-free home rule compared with smokers (aOR: 19.17; 95\% CI: 12.89-28.50). Moreover, non-smokers had lower odds (aOR: 0.35 ; 95\% CI: $0.20-0.61 ; p<0.001$ ) of self-reporting SHS smoke exposure at home. Although two-thirds of the Polish population have adopted a full smoke-free home rule in their homes, smokers continue to lag in adoption rates relative to non-smokers.
\end{abstract}

Keywords: secondhand smoke; smoke-free policy; exposure; tobacco control; prevalence; smoke-free home rule; smoking ban

\section{Introduction}

Secondhand smoke (SHS) is a mixture of smoke generated from burning tobacco products (e.g., cigarettes) and smoke that has been exhaled or breathed out by the smoker [1]. According to the World Health Organization (WHO), SHS exposure contributes to the premature death of approximately 1.2 million people globally each year [2]. Most exposure to SHS occurs in workplaces, homes and cars $[3,4]$. Because there is no safe level of exposure to SHS, public health authorities, including the U.S. Surgeon General [5], the European Commissioner for Health and Consumer Policy [6] and International 
Agency for Research on Cancer [7] have advised that protection is achieved most effectively with comprehensive (i.e., $100 \%$ ) smoke-free policies.

In line with Article 8 of the WHO Framework Convention on Tobacco Control (WHO FCTC), many countries have adopted smoke-free laws designed to provide protection from SHS exposure in workplace and public venues [8]. However, while smoke-free policies have been shown to significantly reduce SHS exposure in work and public places, many children and non-smokers continue to be exposed to SHS in private setting (including homes) where implementation of smoke-free rules is largely voluntary $[9,10]$.

Voluntary smoke-free home rules not only protect non-smokers from SHS exposure, but can also drive changes in smoking behavior [11,12]. The adoption of smoke-free rules in private settings is associated with increased cessation attempts and lower cigarette consumption $[11,13,14]$. Smoke-free homes may also help to prevent relapse among those who have quit smoking [14]. Moreover, adoption of a $100 \%$ smoke-free home rule may decrease the likelihood of smoking initiation among adolescents [15].

The prevalence of complete smoke-free home rules varies by country and global region, ranging from $6.4 \%$ in Indonesia [16], 7.6\% in Pakistan [16], 55.1\% in Japan [17], and up to 83.7\% in the U.S. [18]. The Global Adult Tobacco Survey (GATS; 2008-2011) also reveals substantial variation in home-based SHS exposure, ranging from $17.4 \%$ in Mexico to $73.1 \%$ in Vietnam [19]. Data from the last GATS in Poland (2009-2010) found that only $37.4 \%$ of Poles (50.2\% among nonsmokers and $15.7 \%$ among smokers) were protected by a full smoke-free home rule [20]. Further, $44.2 \%$ of Poles reported exposure to SHS at home in the last 30 days ( $28 \%$ of nonsmokers and $80.9 \%$ of smokers) [21].

Poland has made substantial progress in tobacco control in the past decade, with the adoption of smoking bans in public places, restrictions on advertising and marketing, text health warnings and other broad-based actions in 2010 [22]. Between 2011 and 2019 the prevalence of adult daily smoking (aged 15 and over) decreased from 31\% to 21.0\% [23]. However, it is not known whether the broad-based policy interventions of 2010 and the resulting changes in tobacco use trends have influenced the voluntary adoption of smoke-free rules in private homes. Previous studies suggest that legislative bans on smoking in public venues may also increase the prevalence of homes with a voluntary smoke-free policy [24,25]. Likewise, smoke-free home rules are more likely to be observed in jurisdictions with lower smoking prevalence $[10,16]$.

Therefore, the objectives of this study were to: (1) to assess the prevalence and characteristics of voluntary smoke-free home rules in Poland; and (2) assess the association of smoke-free rules with self-reported SHS exposure in private homes.

\section{Materials and Methods}

\subsection{Study Design and Population}

Data for this study were provided by the Chief Sanitary Inspectorate: a Polish government agency responsible for regular monitoring of tobacco use and prevention policies. A cross-sectional survey was conducted in September 2019 with a nationally representative sample of 1011 individuals aged 15 and over [23]. Data were collected by a specialized survey company using a computer-assisted personal interviewing (CAPI) technique, on behalf of the Chief Sanitary Inspectorate [26]. A random quota sample was selected with an address-based sampling frame [27]. The stratification model was based on demographic data from the national population report and includes gender, age, as well as the size of domicile and the territorial distribution within administrative units.

Participation in the study was voluntary and anonymous. The study protocol was approved by the Ethical Review Board at the Centre of Postgraduate Medical Education, Warsaw, Poland (consent number 51/PB/2020). 


\subsection{Measures}

Smoking status: Respondents were asked about their smoking status, using the questions: "Have you smoked at least 100 cigarettes (or similar amount of other tobacco products) in your lifetime?" and "Do you currently smoke?" Smokers were respondents who reported having smoked at least 100 cigarettes (or other combusted tobacco products) during their lifetime and who reported current smoking (last 30 days). Non-smokers were respondents who reported having smoked fewer than 100 cigarettes during their lifetime and/or do not currently smoke.

Smoke-free rules in home: Respondents were asked about smoke-free rules in their home, using the question: "Is tobacco smoked in your home?" with four possible answers: "Yes, without limitations, i.e., throughout the house" or "Yes, but only in designated, closed areas" or "Yes, but only outside, e.g., on the balcony or terrace" or "No, my home is smoke-free (total ban on smoking)". Based on the response to this question, smoke-free rules were categorized as: full smoke-free home rule (i.e., full ban), partial smoke-free home rule (smoking in designated closed areas and smoking on the balcony or terrace), and no smoke-free home rule.

Secondhand smoke exposure: Exposure to SHS at home in the past month was assessed using the question: "In the last month, were you exposed to second-hand smoke in your home (that is, anyone smoked inside while you were present)?".

Sociodemographics: Questions related to sociodemographic data included: gender, age, marital status, occupational status, educational level, income class, number of household members, number of children living in the home and place of residence. Active occupational status included employees and self-employed; passive occupational status included the unemployed, students or pensioners/retirees (people who have temporarily or permanently left the workforce owing to age or disability). Household income was assessed with the question: "How do you assess your own/your family's financial situation? (High/Medium/Low)". Place of residence was defined by the official administrative definition of rural and urban (residence in a city regardless of the number of inhabitants).

\subsection{Statistical Analysis}

The distribution of categorical variables was shown by weighted frequencies and proportions with $95 \%$ confidence intervals (CI). Categorical variables were compared using the independent samples $\chi^{2}$ test. The univariable and multiple logistic regression analyses were conducted to calculate the odds ratios (ORs) and 95\% confidence interval (CI) of selected variables in relation to the (1) implementation of a full smoke-free home rule in home and (2) exposure to SHS at home. Statistical inference was based on the criterion $p<0.05$.

Associations between smoking status, personal characteristics (gender, age), educational level and housing characteristics (number of household members, having children in home) with implementation of a complete voluntary smoke-free home rule were conducted using logistic regression analyses. Model 1 includes demographic covariates (including gender and age) to assess their association with smoke-free home rule adoption. Model 2 adds educational level (a proxy for socio-economic position). Model 3 adds domestic factors (number of household members and number of children at home).

Additional linear regression models were constructed for the outcome of SHS exposure at home by selected socio-economic factors. Model 1 uses an ordinary least assess the effect of sex, age and smoking status on exposure to SHS at home. Model 2 adds educational level. Model 3 adds selected housing variables (number of household members and number of children at home).

Data were analyzed with SPSS, version 25 (IBM, Armonk, NY, USA).

\section{Results}

Analyses were conducted on responses from $n=1011$ individuals aged 15 and over $(52.1 \%$ female). Table 1 shows the characteristics of the study sample classified by smoking status. There were significant differences $(p<0.05)$ between smokers and non-smokers by gender, age, marital status, 
educational level and number children in home. Nationally, $66.1 \%$ of individuals had $100 \%$ smoke-free home rules, $24.6 \%$ had implemented a partial smoke-free home rule and $9.3 \%$ had not implemented any smoke-free home rules. The majority of non-smokers $(79.8 \%)$ had adopted a full smoke-free home rule (Table 2). Nevertheless, a full smoke-free home rule was declared only by $18.5 \%$ of smokers $(p<0.001)$. More than a third of smokers $(35.0 \%)$ had no voluntary policy regarding smoking in the home.

Table 1. Study sample: characteristics by smoking status.

\begin{tabular}{|c|c|c|c|c|c|c|c|}
\hline \multirow{2}{*}{ Variable } & \multicolumn{2}{|r|}{$\begin{array}{c}\text { Total } \\
\mathrm{N}=1011\end{array}$} & \multicolumn{2}{|r|}{$\begin{array}{c}\text { Smokers } \\
\mathrm{n}=\mathbf{2 2 6}\end{array}$} & \multicolumn{2}{|c|}{$\begin{array}{c}\text { Non-Smokers } \\
\mathrm{n}=785\end{array}$} & \multirow{2}{*}{$p$} \\
\hline & $\mathbf{n}$ & $\begin{array}{l}\text { Weighted } \\
\%(95 \% \text { CI) }\end{array}$ & $\mathbf{n}$ & $\begin{array}{l}\text { Weighted } \\
\%(95 \% \text { CI) }\end{array}$ & $\mathbf{n}$ & $\begin{array}{l}\text { Weighted } \\
\%(95 \% \text { CI })\end{array}$ & \\
\hline \multicolumn{8}{|l|}{ Gender } \\
\hline Men & 484 & $47.9(44.8-51.0)$ & 125 & $55.3(48.8-61.7)$ & 359 & $45.7(42.3-49.2)$ & \multirow{2}{*}{0.01} \\
\hline Women & 527 & $52.1(49.1-55.2)$ & 101 & $44.7(38.4-51.2)$ & 426 & $54.3(50.8-57.7)$ & \\
\hline \multicolumn{8}{|l|}{ Age (years) } \\
\hline 15-19 & 63 & $6.2(4.9-7.9)$ & 1 & $0.4(0.01-2.5)$ & 62 & $7.9(6.2-10.0)$ & \multirow{6}{*}{$<0.001$} \\
\hline $20-29$ & 168 & $16.6(14.5-19.0)$ & 28 & $12.4(8.7-17.3)$ & 140 & $17.8(15.3-20.7)$ & \\
\hline $30-39$ & 195 & $19.3(17.0-21.8)$ & 54 & $23.9(18.8-29.9)$ & 142 & $18.1(15.6-20.9)$ & \\
\hline $40-49$ & 153 & $15.1(13.1-17.5)$ & 43 & $19.0(14.4-24.6)$ & 110 & $14.0(11.8-16.6)$ & \\
\hline $50-59$ & 167 & 16.5 (14.4-18.9) & 46 & $20.4(15.6-26.1)$ & 121 & $15.4(13.1-18.1)$ & \\
\hline $60+$ & 264 & $26.1(23.5-28.9)$ & 54 & $23.9(18.8-29.9)$ & 210 & $26.8(23.8-30.0)$ & \\
\hline \multicolumn{8}{|l|}{ Marital status } \\
\hline Ever married & 744 & $73.6(70.8-76.2)$ & 182 & $80.2(74.5-84.8)$ & 562 & $71.7(68.4-74.7)$ & \multirow{2}{*}{0.01} \\
\hline \multicolumn{7}{|l|}{$\begin{array}{l}\text { Occupational } \\
\text { status }\end{array}$} & \\
\hline Active & 627 & $62.0(59.0-65.0)$ & 144 & $63.7(57.3-68.7)$ & 483 & $61.5(58.1-64.9)$ & \multirow[b]{2}{*}{0.6} \\
\hline Passive & 384 & $38.0(35.0-41.0)$ & 82 & $36.3(30.3-42.7)$ & 302 & $38.5(35.1-41.9)$ & \\
\hline \multicolumn{8}{|l|}{ Education level } \\
\hline $\begin{array}{l}\text { Less than } \\
\text { secondary }\end{array}$ & 453 & $44.8(41.8-47.9)$ & 125 & $55.3(48.8-61.7)$ & 328 & $41.8(38.4-45.3)$ & \multirow[t]{2}{*}{$<0.001$} \\
\hline $\begin{array}{l}\text { Secondary or } \\
\text { above }\end{array}$ & 558 & $55.2(52.1-58.2)$ & 101 & $44.7(38.4-51.2)$ & 457 & $58.2(54.7-61.6)$ & \\
\hline \multicolumn{8}{|l|}{ Income class } \\
\hline High & 232 & $23.0(20.5-25.6)$ & 41 & $18.1(13.7-23.7)$ & 192 & $24.5(21.6-27.6)$ & \multirow{3}{*}{0.1} \\
\hline Medium & 497 & $49.2(46.1-52.2)$ & 116 & $51.3(44.8-57.8)$ & 380 & $48.4(44.9-51.9)$ & \\
\hline Low & 282 & $27.9(25.2-30.7)$ & 69 & $30.5(24.9-36.8)$ & 213 & $27.1(24.1-30.4)$ & \\
\hline \multicolumn{8}{|l|}{$\begin{array}{l}\text { Number of } \\
\text { household } \\
\text { members }\end{array}$} \\
\hline 1 & 231 & $22.9(20.4-25.5)$ & 51 & $22.5(17.5-28.3)$ & 180 & $23.0(20.2-26.0)$ & \multirow{2}{*}{0.9} \\
\hline 2 or more & 780 & $77.1(74.5-79.6)$ & 176 & $77.5(71.7-82.5)$ & 604 & $77.0(74.0-79.9)$ & \\
\hline \multicolumn{8}{|l|}{$\begin{array}{l}\text { Children in } \\
\text { home }\end{array}$} \\
\hline Yes & 232 & $23.0(20.5-25.6)$ & 65 & $28.8(23.3-35.0)$ & 167 & $21.3(18.6-24.3)$ & \multirow{2}{*}{0.02} \\
\hline No & 779 & $77.0(74.4-79.5)$ & 161 & $71.2(65.0-76.8)$ & 618 & 78.7 (75.7-81.5) & \\
\hline \multicolumn{8}{|l|}{$\begin{array}{l}\text { Place of } \\
\text { residence }\end{array}$} \\
\hline Rural & 394 & $39.0(36.0-42.0)$ & 76 & $33.5(27.7-39.9)$ & 318 & 40.5 (37.1-44.0) & \multirow{2}{*}{0.06} \\
\hline Urban & 617 & $61.0(58.0-64.0)$ & 151 & $66.5(60.2-72.3)$ & 467 & $59.5(56.0-62.9)$ & \\
\hline
\end{tabular}

SHS exposure in the home during past month was reported by $6.1 \%$ of respondents $(11.5 \%$ of smokers and $4.5 \%$ of non-smokers; $p<0.001)$. The lowest level of SHS exposure $(1.8 \%)$ was observed among respondents with a full smoke-free home rule (Table 2).

The results of the univariate and multivariate regression analyses are presented in Tables 3 and 4. In univariate analysis, non-smokers (OR: 17.20; 95\% CI: 11.79-25.07; $p<0.001$ ) and those with a secondary education or higher (OR: $1.37 ; 95 \%$ CI: 1.05-1.78; $p<0.05)$ had greater odds of reporting a full smoke-free home rule (see Table 3). When adjusted for all covariables, only smoking status was significantly $(p<0.001)$ associated with greater odds of having a $100 \%$ smoke-free home rule (non-smokers aOR: 19.17; 95\% CI: 12.89-28.50). Non-smokers had lower odds (aOR: 0.35; 95\% CI: $0.20-0.61 ; p<0.001$ ) of secondhand smoke exposure at home, even after controlling for other factors (Table 4). 
Table 2. Proportion of homes with smoke-free rules and exposure to secondhand smoke (SHS) at home among in a representative sample aged 15 and over in Poland, by smoking status.

\begin{tabular}{|c|c|c|c|c|c|c|}
\hline \multirow{2}{*}{$\begin{array}{c}\text { Type of } \\
\text { Smoke-Free } \\
\text { Rules }\end{array}$} & \multicolumn{2}{|c|}{ Smoke-Free Home Rules } & \multirow[t]{2}{*}{$p$} & \multicolumn{2}{|c|}{$\begin{array}{l}\text { Exposure to SHS at Home } \\
\text { (Answered Yes) }\end{array}$} & \multirow[t]{2}{*}{$p$} \\
\hline & $\begin{array}{c}\text { Smokers } \\
(n=226) \\
\%(95 \% \mathrm{CI})\end{array}$ & $\begin{array}{c}\text { Non-Smokers } \\
(n=785) \\
\%(95 \% \text { CI })\end{array}$ & & $\begin{array}{c}\text { Smokers } \\
(\mathrm{n}=226) \\
\%(95 \% \mathrm{CI})\end{array}$ & $\begin{array}{c}\text { Non-Smokers } \\
(\mathbf{n}=785) \\
\%(95 \% \mathrm{CI})\end{array}$ & \\
\hline Full rule & $18.6(14.1-24.2)$ & $79.8(76.8-82.4)$ & & $2.4(0.4-12.3)$ & $1.8(1.0-3.1)$ & \\
\hline Partial rule & $46.5(40.1-53.0)$ & $18.5(15.9-21.3)$ & $<0.001$ & $8.6(4.6-15.5)$ & $11.7(7.5-18.0)$ & $<0.001$ \\
\hline No rules & $35.0(29.0-41.4)$ & $1.8(1.1-3.0)$ & & $20.3(12.9-30.4)$ & $57.1(32.6-78.6)$ & \\
\hline
\end{tabular}

Table 3. Implementation of voluntary smoke-free home rules by selected socioeconomic factors in a representative sample aged 15 and over in Poland: Odds ratios (OR) and 95\% confidence intervals (95\% CI). ( $\mathrm{N}=1011)$.

\begin{tabular}{|c|c|c|c|c|c|}
\hline \multirow[b]{2}{*}{ Variable } & \multirow{2}{*}{$\begin{array}{c}\text { Yes } \\
\text { n (\%) }\end{array}$} & \multirow{2}{*}{$\begin{array}{c}\text { Simple } \\
\text { Regression } \\
\text { OR }(95 \% \text { CI) }\end{array}$} & \multicolumn{3}{|c|}{ Multiple Regression } \\
\hline & & & Model 1 & $\begin{array}{c}\text { Model } 2 \\
\text { aOR }(95 \% \text { CI) }\end{array}$ & Model 3 \\
\hline \multicolumn{6}{|l|}{$\begin{array}{l}\text { Smoking } \\
\text { status }\end{array}$} \\
\hline Smoker & $42(18.6)$ & Reference & Reference & Reference & Reference \\
\hline Non-smoker & $626(79.8)$ & $\begin{array}{c}17.20 \\
(11.79-25.07) * *\end{array}$ & $\begin{array}{c}18.81 \\
(12.74-27.78) * *\end{array}$ & $\begin{array}{c}18.70 \\
(12.62-27.72) * *\end{array}$ & $\begin{array}{c}19.17 \\
(12.89-28.50)^{* *}\end{array}$ \\
\hline \multicolumn{6}{|l|}{ Gender } \\
\hline Women & $355(67.4)$ & Reference & Reference & Reference & Reference \\
\hline Men & $313(64.7)$ & $0.89(0.69-1.16)$ & $1.11(0.81-1.51)$ & $1.11(0.81-1.52)$ & $1.14(0.83-1.57)$ \\
\hline \multicolumn{6}{|l|}{ Age (years) } \\
\hline $15-19$ & $44(69.8)$ & Reference & Reference & Reference & Reference \\
\hline $20-29$ & $115(68.5)$ & $0.91(0.49-1.71)$ & $1.49(0.77-2.90)$ & $1.46(0.73-2.93)$ & $1.43(0.71-2.88)$ \\
\hline $30-39$ & $120(61.2)$ & $0.67(0.36-1.24)$ & $1.46(0.76-2.81)$ & $1.43(0.72-2.83)$ & $1.27(0.62-2.57)$ \\
\hline $40-49$ & $103(67.3)$ & $0.88(0.47-1.67)$ & $2.26(1.12-4.56)$ * & $2.21(1.07-4.57)$ * & $2.08(0.99-4.32)$ \\
\hline $50-59$ & 109 (64.9) & $0.79(0.42-1.47)$ & $1.88(0.95-3.72)$ & $1.85(0.92-3.72)$ & $1.91(0.94-3.88)$ \\
\hline $60+$ & $177(67.1)$ & $0.87(0.48-1.58)$ & $1.62(0.86-3.04)$ & $1.60(0.85-3.03)$ & $1.63(0.84-3.16)$ \\
\hline \multicolumn{6}{|l|}{$\begin{array}{l}\text { Education } \\
\text { level }\end{array}$} \\
\hline $\begin{array}{l}\text { Less than } \\
\text { secondary }\end{array}$ & $282(62.3)$ & Reference & & Reference & Reference \\
\hline $\begin{array}{l}\text { Secondary } \\
\text { or above }\end{array}$ & $386(69.2)$ & $1.37(1.05-1.78)$ * & & $1.04(0.74-1.45)$ & $1.04(0.74-1.46)$ \\
\hline \multicolumn{6}{|l|}{$\begin{array}{l}\text { Number of } \\
\text { household } \\
\text { members }\end{array}$} \\
\hline 1 & $155(67.1)$ & Reference & & & Reference \\
\hline 2 or more & $514(65.9)$ & $0.95(0.70-1.30)$ & & & $0.91(0.61-1.37)$ \\
\hline \multicolumn{6}{|l|}{$\begin{array}{l}\text { Children } \\
\text { in home }\end{array}$} \\
\hline No & $518(66.5)$ & Reference & & & Reference \\
\hline Yes & $150(64.7)$ & $0.93(0.69-1.27)$ & & & $1.36(0.87-2.12)$ \\
\hline
\end{tabular}


Table 4. Exposure to secondhand smoke at home by selected socio-economic factors in a representative sample aged 15 and over in Poland: Odds ratios (OR) and 95\% confidence intervals (95\% CI). (N = 1011).

\begin{tabular}{|c|c|c|c|c|c|}
\hline \multirow[b]{2}{*}{ Variable } & \multirow[b]{2}{*}{$\begin{array}{c}\text { Yes } \\
\text { n (\%) }\end{array}$} & \multirow{2}{*}{$\begin{array}{c}\text { Simple } \\
\text { Regression } \\
\text { OR }(95 \% \text { CI) }\end{array}$} & \multicolumn{3}{|c|}{ Multiple Regression } \\
\hline & & & Model 1 & $\begin{array}{c}\text { Model } 2 \\
\text { aOR (95\% CI) }\end{array}$ & Model 3 \\
\hline \multicolumn{6}{|l|}{ Smoking status } \\
\hline Smoker & $26(11.5)$ & Reference & Reference & Reference & Reference \\
\hline Non-smoker & $36(4.6)$ & $0.37(0.22-0.63)^{* *}$ & $0.35(0.20-0.60)^{* *}$ & $0.36(0.21-0.63)^{* *}$ & $0.35(0.20-0.61)^{* *}$ \\
\hline \multicolumn{6}{|l|}{ Gender } \\
\hline Women & $31(5.9)$ & Reference & Reference & Reference & Reference \\
\hline Men & $30(6.2)$ & $1.07(0.64-1.79)$ & $0.97(0.58-1.64)$ & $0.94(0.56-1.59)$ & $0.90(0.53-1.53)$ \\
\hline \multicolumn{6}{|l|}{ Age (years) } \\
\hline $15-29$ & $16(6.9)$ & Reference & Reference & Reference & Reference \\
\hline $30-49$ & $20(5.8)$ & $0.82(0.43-1.56)$ & $0.70(0.36-1.36)$ & $0.65(0.34-1.27)$ & $0.64(0.32-1.30)$ \\
\hline $50+$ & $25(5.8)$ & $0.82(0.42-1.60)$ & $0.67(0.33-1.33)$ & $0.68(0.34-1.37)$ & $0.76(0.37-1.56)$ \\
\hline \multicolumn{6}{|l|}{ Education level } \\
\hline Less than secondary & $35(7.7)$ & Reference & & Reference & Reference \\
\hline Secondary or above & $27(4.8)$ & $0.62(0.37-1.04)$ & & $0.66(0.39-1.14)$ & $0.66(0.39-1.13)$ \\
\hline \multicolumn{6}{|l|}{$\begin{array}{l}\text { Number of household } \\
\text { members }\end{array}$} \\
\hline 1 & $12(5.2)$ & Reference & & & Reference \\
\hline 2 or more & $50(6.4)$ & $1.26(0.66-2.42)$ & & & $1.33(0.67-2.67)$ \\
\hline \multicolumn{6}{|l|}{ Children in home } \\
\hline No & $50(6.4)$ & Reference & & & Reference \\
\hline Yes & $12(5.2)$ & $0.80(0.42-1.53)$ & & & $0.64(0.30-1.35)$ \\
\hline
\end{tabular}

\section{Discussion}

This study revealed that $66.1 \%$ of Polish adults report having a full smoke-free home rule. This outcome represents a marked increase over the rate of 37\% reported in 2010. Even so, the current proportion of Polish households with a complete home smoking ban is lower than recently reported in the U.S. (83.7\%) [18], but higher compared to other countries, including Indonesia (6.4\%) [16], Pakistan (7.6\%) [16] or Japan (55.1\%) [17]. Despite a dramatic increase in home-based protection from SHS exposure from 2010 to 2019, a substantial proportion of Poles still live in homes with limited or no protection from SHS. The lack of protection is not evenly distributed across the population: non-smokers had 19.2 times higher odds of having a $100 \%$ smoke-free home compared to smokers. One practical response to this finding would be to implement future tobacco control initiatives that emphasize the benefit of adopting a full smoke-free home rule among smokers. In addition, we found that $6.1 \%$ of Polish adults reported being exposed to SHS in the home. Even though home-based SHS exposure occurs among a relatively low proportion of Polish adults, continued efforts are required to further reduce exposure, through targeted communications highlighting the health risks of SHS and the need to adopt a total smoke-free home rule.

While the prevalence of total smoke-free home rules among non-smokers increased by $59 \%$ (from $50.2 \%$ to $79.8 \%$ ) between 2010 to 2019 , the prevalence among smokers increased by just $18.5 \%$ (from $15.7 \%$ to $18.6 \%$ ) [28]. This finding is reflected in data on home smoking rule adoption rates across the EU $[29,30]$. According to the EUREST-PLUS Project, which includes six EU countries [29], the proportion of $100 \%$ smoke-free homes among smokers in 2016 varied from $13.1 \%$ in Spain to $35.5 \%$ in Hungary [29]. In our study, a full smoke-free home rule was reported by $18.6 \%$ of smokers, which is almost half the rate observed in Hungary [28]. In a study carried out between 2011 and 2015, $61 \%$ of Italians adopted a full smoke-free home rule (32\% of smokers and $69 \%$ of non-smokers) [30], comparing closely to findings observed in the present study. Because data on the prevalence of complete voluntary smoke-free home rules in EU households are limited, this topic should be included in future Eurobarometer surveys.

Between 2009-2011 and 2019, a substantial proportion of households adopted a total smoke free home rule, representing remarkable progress towards protection from home-based SHS exposure [28]. The proportion of Poles exposed to SHS at home decreased seven-fold in the past decade, from $44.2 \%$ in 
2009-2011 to 6.1\% in 2019 [28]. Exposure to SHS at home decreased significantly among both smokers (from $80.9 \%$ to $11.5 \%$ ) and non-smokers (from $28 \%$ to $4.5 \%$ ) [28]. An analysis based on data from 15 countries participating in GATS revealed that home SHS exposure is higher among those of lower income and educational attainment [19]. In contrast, we found no association between socio-economic factors and the prevalence of home SHS exposure. Indeed, our findings revealed that a total home smoke-free home rule was the only consistent factor associated with lower SHS exposure. Our study was carried out in the general population and the percentage of subjects exposed to SHS at home was relatively low $(n=62)$. The failure to observe an association between socio-economic factors and home SHS exposure is likely the consequence of a lack of statistical power, although confounding factors in the model, particularly smoking status, may also undermine any potential association. Certainly, further research will be needed to determine whether SHS exposure is associated with low SES in Poland.

The precise reasons for accelerated adoption of smoke free home rules in Poland cannot be determined in this cross-sectional survey. Nonetheless, there are a number of factors that could impact public attitudes towards the adoption of smoke-free rules. Of particular significance are data showing that the prevalence of daily smoking among adults Poles (aged 15 and over) fell from 31\% in 2011 to $21 \%$ between 2011-2019 [23]. With a lower national rate of adult smoking, it is reasonable to assume that there will be increasingly fewer households where smoking continues to be allowed indoors. Secondly, in 2010 Poland adopted new tobacco control regulations that disallowed smoking in workplaces and 12 other types of public venues, including health care, hospitality and sporting venues [22]. Elimination of smoking in public venues is perceived as a powerful tool to shape social norms that discourage tobacco use, and so may promote the voluntary adoption of smoke-free home rules [31]. This hypothesis is supported by previous studies on tobacco control carried out biannually by the Chief Sanitary Inspectorate [23,28]. According to the 2013 national cross-sectional survey on tobacco use in Poland, $55 \%$ of respondents ( $72 \%$ of non-smokers and $14 \%$ of smokers) had adopted a full smoke-free home rule [28]. Within three years of the adoption of Poland's smoke-free law, the prevalence of voluntary smoke-free home rules increased by $47 \%$ (from $37.4 \%$ in $2009-2010$ to $55.0 \%$ in 2013 ). However, in the next six years, from 2013-2019, the proportion of 100\% smoke-free homes in Poland increased further by only $20.2 \%$. One interpretation of these trends is that the changing trajectory of the adoption of smoke-free home rules was initially driven by the introduction of a ban on tobacco use in public places in 2010. The national smoke-free laws may have been a particularly potent signal of changing social acceptability of smoking in the presence of non-smokers, including in private homes.

Despite the observation of a significant increase in the proportion of households with a full smoke-free home rule, there is still progress to be made. Our findings indicate that smokers are less likely to have a full smoke-free home rule and therefore are at higher risk of SHS exposure in the home. While wide-ranging information campaigns have been conducted to inform the public about public smoke-free laws in Poland, similar campaigns to promote voluntary smoke-free home rules have not been undertaken. In addition, ongoing efforts are needed to inform the public about the health risks of SHS exposure. According to the Public Opinion Research Center (CBOS) data, 42\% of Poles reported that experiencing smoking in their presence is acceptable [32]. Moreover, between 1993 and 2016, the percentage of Poles who declared a commitment to protecting their own health increased by 27 points in total [33]. Social changes in the pro-health behaviors of Poles may have an impact on the implementation of smoke-free home rules [33]. Smoke-free home rules may themselves shape social norms and discourage tobacco use. Children who are raised in smoke-free homes are less likely to start smoking in the future $[10,11]$. Thus, efforts to promote smoke-free homes in Poland are likely to yield substantial longer-term impact by rendering smoking less socially acceptable, thereby reducing smoking rates and lowering SHS exposure.

This study has several limitations. First, our analytic approach assumed a simple random sample rather than using techniques appropriate for complex survey design, which may elevate the likelihood of Type I error. Nonetheless, we note that the major significant outcomes involved the influence of 
smoking status on smoke-free rule status and secondhand smoke exposure; a likely robust effect that is consistent with published research. Second, SHS exposure was defined based on self-reported data. We cannot exclude potential misinterpretation of questions related to SHS exposure, especially among smokers, which may invoke error such as demand bias or recall bias. Third, self-reported SHS exposure was not verified by objective measures of ambient SHS (such as passive nicotine dosimetry or concentration of $\mathrm{PM}_{2.5}$ particulate matter) or biomarkers of SHS exposure [34]. Environmental or biochemical indices of SHS exposure may help to address problems of under- or over-reporting SHS exposure.

Despite these limitations, the data reported here represent the most comprehensive insight to date on voluntary smoke-free home rules in Poland, while highlighting the significant practical implications of tobacco control actions that may increase the adoption of smoke free home rules.

\section{Conclusions}

Although two-thirds of the Polish population have adopted a total smoke free home rule, smokers lag in their rate of adoption relative to non-smokers. The present data underscore the importance of adopting a full smoke-free home rule to protect household members from exposure to secondhand smoke.

Author Contributions: Conceptualization, M.J., J.P., D.K., and V.W.R.; methodology, M.J., J.P., W.S.Z., D.K., W.W., M.G. and V.W.R.; validation, M.J. and J.P.; formal analysis, M.J., J.P., W.S.Z., D.K. and V.W.R.; investigation M.J., J.P., W.S.Z., D.K., W.W. and M.G.; resources, M.J. and J.P.; data curation, M.J., J.P. and W.S.Z.; writing-original draft preparation, M.J, J.P., W.S.Z., D.K. and V.W.R.; writing—review and editing, W.W., M.G. and V.W.R. visualization, M.J., J.P. and V.W.R.; supervision, J.P. All authors have read and agreed to the published version of the manuscript.

Funding: M.J. acknowledges support from the Polish National Agency for Academic Exchange as part of the Walczak Scholarship Programme (grant No. PPN/WAL/2019/1/00011/U/00001).

Conflicts of Interest: The authors declare no conflict of interest.

\section{References}

1. Kim, A.; Ko, H.J.; Kwon, J.H.; Lee, J.M. Exposure to Secondhand Smoke and Risk of Cancer in Never Smokers: A Meta-Analysis of Epidemiologic Studies. Int. J. Environ. Res. Public Health 2018, 15, 1981. [CrossRef] [PubMed]

2. World Health Organization (WHO). Tobacco. Available online: https:/www.who.int/news-room/fact-sheets/ detail/tobacco (accessed on 26 July 2020).

3. Sureda, X.; Fernández, E.; López, M.J.; Nebot, M. Secondhand tobacco smoke exposure in open and semi-open settings: A systematic review. Environ. Health Perspect. 2013, 121, 766-773. [CrossRef] [PubMed]

4. Mlinarić, M.; Hoffmann, L.; Kunst, A.E.; Schreuders, M.; Willemsen, M.C.; Moor, I.; Richter, M. Explaining mechanisms that influence smoke-free implementation at the local level: A realist review of smoking bans. Nicotine Tob. Res. 2019, 21, 1609-1620. [CrossRef] [PubMed]

5. U.S. Department of Health and Human Services. The Health Consequences of Smoking—50 Years of Progress: A Report of the Surgeon General. Atlanta: U.S. Department of Health and Human Services, Centers for Disease Control and Prevention, National Center for Chronic Disease Prevention and Health Promotion, Office on Smoking and Health. 2014. Available online: https://www.cdc.gov/tobacco/data_statistics/sgr/50thanniversary/index.htm (accessed on 26 July 2020).

6. European Commissioner for Health and Consumer Policy. Tobacco in the EU: Exposure to Secondhand Smoke Reduced, But Still Too High, Says Commission Report. Available online: https:/ec.europa.eu/ commission/presscorner/detail/en/IP_13_147 (accessed on 23 July 2020).

7. International Agency for Research on Cancer. IARC Monographs on the Evaluation of Carcinogenic Risks to Humans: Tobacco Smoke and Involuntary Smoking; IARC: Lyon, France, 2004; Volume 83, Available online: https://monographs.iarc.fr/wp-content/uploads/2018/06/mono83.pdf (accessed on 23 July 2020).

8. Framework Convention on Tobacco Control; World Health Organization (WHO): Geneva, Switzerland, 2003; Available online: http://www.who.int/fctc/about/en/ (accessed on 23 July 2020). 
9. Kabir, Z.; Manning, P.J.; Holohan, J.; Keogan, S.; Goodman, P.G.; Clancy, L. Second-hand smoke exposure in cars and respiratory health effects in children. Eur. Respir. J. 2009, 34, 629-633. [CrossRef]

10. Xi, B.; Liang, Y.; Liu, Y.; Yan, Y.; Zhao, M.; Ma, C.; Bovet, P. Tobacco use and second-hand smoke exposure in young adolescents aged 12-15 years: Data from 68 low-income and middle-income countries. Lancet Glob. Health 2016, 4, e795-e805. [CrossRef]

11. Fichtenberg, C.M.; Glantz, S.A. Effect of smoke-free workplaces on smoking behaviour: Systematic review. BMJ 2002, 325, 188. [CrossRef]

12. Hyland, A.; Higbee, C.; Travers, M.J.; Van Deusen, A.; Bansal-Travers, M.; King, B.; Cummings, K.M. Smoke-free homes and smoking cessation and relapse in a longitudinal population of adults. Nicotine Tob. Res. 2009, 11, 614-618. [CrossRef]

13. Hopkins, D.P.; Razi, S.; Leeks, K.D.; Kalra, G.P.; Chattopadhyay, S.K.; Soler, R.E.; Task Force on Community Preventive Services. Smokefree policies to reduce tobacco use. A systematic review. Am. J. Prev. Med. 2010, 38, S275-S289. [CrossRef]

14. Mills, A.L.; Messer, K.; Gilpin, E.A.; Pierce, J.P. The effect of smoke-free homes on adult smoking behavior: A review. Nicotine Tob. Res. 2009, 11, 1131-1141. [CrossRef] [PubMed]

15. Albers, A.B.; Biener, L.; Siegel, M.; Cheng, D.M.; Rigotti, N. Household smoking bans and adolescent antismoking attitudes and smoking initiation: Findings from a longitudinal study of a Massachusetts youth cohort. Am. J. Public Health. 2008, 98, 1886-1893. [CrossRef] [PubMed]

16. Owusu, D.; Quinn, M.; Wang, K.; Williams, F.; Mamudu, H.M. Smokefree home rules and cigarette smoking intensity among smokers in different stages of smoking cessation from 20 low-and-middle income countries. Prev. Med. 2020, 132, 106000. [CrossRef]

17. Shojima, K.; Tabuchi, T. Voluntary home and car smoke-free rules in Japan: A cross-sectional study in 2015. BMJ Open 2019, 9, e024615. [CrossRef] [PubMed]

18. Kruger, J.; Jama, A.; Homa, D.H.; Babb, S.D.; King, B.A. Smoke-free home and vehicle rules by tobacco use status among US adults. Prev. Med. 2015, 78, 9-13. [CrossRef]

19. Nazar, G.P.; Lee, J.T.; Arora, M.; Millett, C. Socioeconomic inequalities in secondhand smoke exposure at home and at work in 15 low- and middle-income countries. Nicotine Tob. Res. 2016, 18, 1230-1239. [CrossRef] [PubMed]

20. Kaleta, D.; Fronczak, A.; Usidame, B.; Dziankowska-Zaborszczyk, E.; Makowiec-Dąbrowska, T.; Wojtysiak, P. Implementation of smoke-free homes in Poland. Int. J. Occup. Med. Environ. Health 2016, 29, 137-148. [CrossRef]

21. WHO Regional Office for Europe. Global Adult Tobacco Survey Poland 2009-2010. Available online: https://www.who.int/tobacco/surveillance/en_tfi_gats_poland_report_2010.pdf (accessed on 25 July 2020).

22. Pinkas, J.; Szymański, J.; Poznański, D.; Wierzba, W. Smoke-free policy in Poland on the example of the implementation into national law of the European Parliament and Council Directive 2014/40/EU of 3 April 2014 on the approximation of laws, regulations and administrative provisions of the Member States concerning the production, presentation and sale of tobacco and related products, and repealing Directive 2001/37/WE. Ann. Agric. Environ. Med. 2016, 23, 395-398. [PubMed]

23. Pinkas, J.; Kaleta, D.; Zgliczyński, W.S.; Lusawa, A.; Wrześniewska-Wal, I.; Wierzba, W.; Gujski, M.; Jankowski, M. The prevalence of tobacco and e-cigarette use in Poland: A 2019 nationwide cross-sectional survey. Int. J. Environ. Res. Public Health 2019, 16, 4820. [CrossRef]

24. Cheng, K.W.; Glantz, S.A.; Lightwood, J.M. Association between smokefree laws and voluntary smokefree-home rules. Am. J. Prev. Med. 2011, 41, 566-572. [CrossRef]

25. Monson, E.; Arsenault, N. Effects of enactment of legislative (public) smoking bans on voluntary home smoking restrictions: A review. Nicotine Tob. Res. 2017, 19, 141-148. [CrossRef]

26. Kissinger, L.; Lorenzana, R.; Mittl, B.; Lasrado, M.; Iwenofu, S.; Olivo, V.; Helba, C.; Capoeman, P.; Williams, A.H. Development of a computer-assisted personal interview software system for collection of tribal fish consumption data. Risk Anal. 2010, 30, 1833-1841. [CrossRef]

27. Central Statistical Office. National Official Register of the Territorial Division of the Country. Available online: http://eteryt.stat.gov.pl/eTeryt/english.aspx (accessed on 15 October 2019).

28. Kantar Public for Chief Sanitary Inspectorate. A Report from a Nationwide Survey on Attitudes Towards Smoking. Available online: https://gis.gov.pl/wp-content/uploads/2018/04/Postawy-Polak\%C3\%B3wdopalenia-tytoniu-Raport-2017.pdf (accessed on 22 July 2020). 
29. Fu, M.; Castellano, Y.; Tigova, O.; Kyriakos, C.N.; Fong, G.T.; Mons, U.; Zatoński, W.A.; Agar, T.K.; Quah, A.C.K.; Trofor, A.C.; et al. Prevalence and correlates of different smoking bans in homes and cars among smokers in six countries of the EUREST-PLUS ITC Europe Surveys. Tob. Induc. Dis. 2018, 16, A8.

30. Gallus, S.; Lugo, A.; Gorini, G.; Colombo, P.; Pacifici, R.; Fernandez, E. Voluntary home smoking ban: Prevalence, trend and determinants in Italy. Eur. J. Public Health 2016, 26, 841-844. [CrossRef]

31. Mons, U.; Nagelhout, G.E.; Allwright, S.; Guignard, R.; van den Putte, B.; Willemsen, M.C.; Fong, G.T.; Brenner, H.; Pötschke-Langer, M.; Breitling, L.P. Impact of national smoke-free legislation on home smoking bans: Findings from the International Tobacco Control Policy Evaluation Project Europe Surveys. Tob. Control 2013, 22, e2-e9. [CrossRef] [PubMed]

32. Centre for Public Opinion Research. Report from the Survey: Tobacco Use in Poland (no. 104/2019). Available online: https://cbos.pl/SPISKOM.POL/2019/K_104_19.PDF (accessed on 25 July 2020).

33. Centre for Public Opinion Research. Report from the survey: Health and Pro-Health Behavior of Poles (no. 138/2016). Available online: https://www.cbos.pl/SPISKOM.POL/2016/K_138_16.PDF (accessed on 25 July 2020).

34. Mattes, W.; Yang, X.; Orr, M.S.; Richter, P.; Mendrick, D.L. Biomarkers of tobacco smoke exposure. Adv. Clin. Chem. 2014, 67, 1-45.

Publisher's Note: MDPI stays neutral with regard to jurisdictional claims in published maps and institutional affiliations.

(C) 2020 by the authors. Licensee MDPI, Basel, Switzerland. This article is an open access article distributed under the terms and conditions of the Creative Commons Attribution (CC BY) license (http://creativecommons.org/licenses/by/4.0/). 